\title{
U WAVE INVERSION
}

\author{
BY
}

\author{
J. H. PALMER \\ From the Royal Victoria and the Queen Mary Veterans' Hospitals, Montreal
}

Received July 7, 1948

The $U$ wave, when first recognized by Einthoven (1906) in the earliest days of electrocardiography, was considered by him to be pathological. Since then the normality of upright $U$ waves, except perhaps in cases where they are unusually high (Katz, 1946), has been generally conceded. Various hypotheses have been advanced to explain the $U$ wave, of which the most satisfactory is that of Hoff and Nahum (1938) who concluded on experimental grounds that it undoubtedly forms part of the ventricular complex, and is coincident in time with the supernormal phase.

The number of papers on the clinical significance of the $U$ wave is small, and reflects the scant attention that seems to have been paid to it by most cardiologists. Important articles however are those of Nahum and Hoff (1939), Papp (1940), and Solarz and Elek (1943), and to them the reader is referred for comprehensive reviews of the subject.

Inversion of $U$ has been considered pathological by most authors. Nahum and Hoff found it in association with coronary, rheumatic, hypertensive, and pulmonary heart disease. Papp reported it in coronary disease and in hypertension. Solarz and Elek found 94 cases of $U$ wave inversion in 1000 cases studied; they report on its association with the left heart strain pattern, intraventricular block, and anterior and posterior wall infarction.

\section{Negative U in Induced Angina}

The writer's interest in negative $U$ waves was stimulated by noticing their appearance in the afterexercise tracing of a patient with angina pectoris. Subsequently six further such patients were found. All were males, and in all of them pain was easily induced by effort. None gave a history of a previous clinical attack of coronary occlusion. Six of the seven had hypertension; all had cardiac $\mathrm{X}$-ray silhouettes that were within the normal range. In all except one (Case 7) test exercise was given to the point of just inducing pain, and the tracing was made as soon afterwards as possible. Table I shows the degrees of $U$ wave positivity and negativity both

\section{TABLE I}

THE U WAVe Before AND AFTer EXercise in ANgina Pectoris

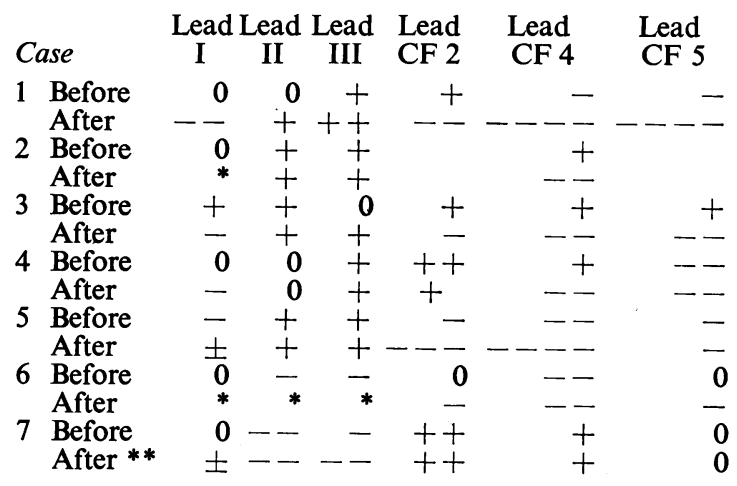

$0=$ isoelectric. $\quad+$ or $-=$ less than $0.5 \mathrm{~mm}$. $+=$ positive. ++++ or $---=1.5$ to $2.0 \mathrm{~mm}$.

$-=$ negative.

*Pulse rate 100 or more.

$\pm=$ diphasic.

**Exercise not carried to point of inducing pain.

before and after exercise; in Table II are listed any other abnormal features of the electrocardiograms, as well as certain clinical data.

In the control (or before-exercise) tracings, $U$ was negative in one or more leads in five of the seven cases. In two of this five $U$ was inverted in the chest leads only, in two it was inverted in both chest and limb leads, and in one in limb leads only.

It will be seen from Table $I$ that in the six cases in which exercise was carried to the point of inducing pain, $U$ became, after exercise, either: (a) more negative if it was already inverted; (b) negative in additional leads in which it had previously been positive or isoelectric; or (c) both (a) and (b). Maximum negativity in these six was always in one 
TABLE II

Findings, in Seven Patients with Angina Pectoris showing U Wave Inversion

\begin{tabular}{|c|c|c|c|c|c|}
\hline Case & Age & $B P$ & $\begin{array}{l}\text { Duration of } \\
\text { Angina }\end{array}$ & \multicolumn{2}{|c|}{ Before Exercise Electrocardiogram } \\
\hline 1 & 46 & $250 / 130$ & 2 mth. & $\begin{array}{l}\text { Intraventricular conduction defect } \\
\text { (QRS=0・11 sec.); T negative in I, } \\
\text { CF } 2, \mathbf{C F} 4 \text {, and CF } 5 \text {. }\end{array}$ & $\begin{array}{l}\text { Depression RS-T in } I \text {; less nega- } \\
\text { tivity } T \text { in chest leads. }\end{array}$ \\
\hline 2 & 65 & $190 / 95$ & $1 \mathrm{yr}$. & Diphasic T in CF 4. & $\begin{array}{l}\text { Depressed RS-T in II and III; } \\
\text { positive T in CF } 4 .\end{array}$ \\
\hline 3 & 43 & $160 / 105$ & $2 \mathrm{yr}$. & None. & $\begin{array}{l}\text { Depression RS-T in CF 4; " coron- } \\
\text { ary " type positive } T \text { waves in } \\
\text { CF } 4 \text { which later became negative. }\end{array}$ \\
\hline 4 & 61 & $170 / 190$ & $10 \mathrm{yr}$. & $\begin{array}{l}\text { Diphasic } \mathrm{T} \mathrm{I} \text { and } \mathrm{T} \text { II } \text {; negative } \mathrm{T} \\
\text { in CF } 5 .\end{array}$ & $\begin{array}{l}\text { Depression RS-T in CF } 4 \text {; " coron- } \\
\text { ary" type positive } T \text { waves in } \\
\text { CF } 2 \text { and CF } 4 \text {. }\end{array}$ \\
\hline 5 & 36 & $120 / 105$ & $3 \mathrm{mth}$. & Negative $T$ in $C F 2, C F 4$, and CF 5. & $\begin{array}{l}\text { T positive and of " coronary" type } \\
\text { in CF } 2 \text { and CF } 4 \text {. }\end{array}$ \\
\hline 6 & 43 & $120 / 80$ & $3 \mathrm{mth}$. & $\begin{array}{l}\text { Notching of } S \text { in CF } 2 \text {; depressed } \\
\text { RS-T }(0.5 \mathrm{~mm} .) \text { in CF } 4 .\end{array}$ & Depression RS-T in CF 4. \\
\hline 7 & 58 & $190 / 90$ & $5 \mathrm{yr}$. & None. & None.* \\
\hline
\end{tabular}

or more of the chest leads. In five of them it was possible to recognize a pattern consisting of inversion in lead I and in the chest leads, greatest in CF 4 with positivity of U in lead III (see Fig. 1); in one case a positive $U$ appeared in lead III where previously it had been isoelectric, and in another the positivity of $U$ in lead III increased. This pattern is reminiscent of the pattern of $\mathrm{T}$ wave inversion seen in anterior coronary occlusion. In another case $U$ was negative in leads II, III, and CF 4 before exercise, and after exercise became negative also in CF 2 and CF 5. In Case 7, where exercise was not carried to the point of inducing pain, $U$ was negative in II and III, but positive in CF 2 and CF 4.

In three cases there developed with exercise, in certain of the chest leads, an interesting pattern comprised of sharply pointed positive $T$ waves with symmetrical shoulders which have previously been described as "coronary T waves" (Katz, 1946), and negative $U$ waves (see Fig. 2 and 3). This pattern has been seen by us only in patients with coronary insufficiency; whether or not it should be considered pathognomonic of this condition will depend upon further observations.

A discordancy in the direction of the development of $T$ wave and $U$ wave potentials was seen in two patients. In Case 5 (see Fig. 3) the T wave had, in the control tracing, been negative; its change to positive with exercise was concurrent with the development of increased negativity of $U$. Conversely, in Case 3 (see Fig. 2) a negative $U$, which made its appearance immediately after exercise, was found to disappear five minutes later at the same time as $T$ became negative.

\section{Negative U as Isolated Abnormality}

Tracings in which $U$ wave inversion constitutes the only cardiographic abnormality are probably uncommon. Nahum and Hoff (1939) reported two cases, but the high T wave in lead IVR in one of them (their Fig. 8) is probably abnormal. In Papp's (1940) case there is a pathologically low takeoff of the RS-T segment in IVR. Solarz and Elek (1943) state that " no abnormal U waves were found in the absence of other abnormalities in the electrocardiogram," and that therefore " there is not much diagnostic value in the recognition of $U$ wave patterns." It seems difficult however for them to justify this conclusion, in view of their having studied only tracings that had been chosen for their abnormality. Katz (1946) observes that abnormalities of $U$ rarely occur in the absence of abnormalities of S-T-T and believes that "little clinical weight would be given to an electrocardiogram in which the only deviation from the normal was in the U wave."

The writer has records of three cases in which no trace of abnormality other than $U$ wave inversion could be made out. 'The first patient (see Fig. 4) suffered from Paget's disease and severe hypertension, and at the time that the tracing was made was actually in congestive failure. The second had angina pectoris (Case 7 of present series). The third was a patient suffering from polycystic kidney disease with uræmia and severe hypertension. 


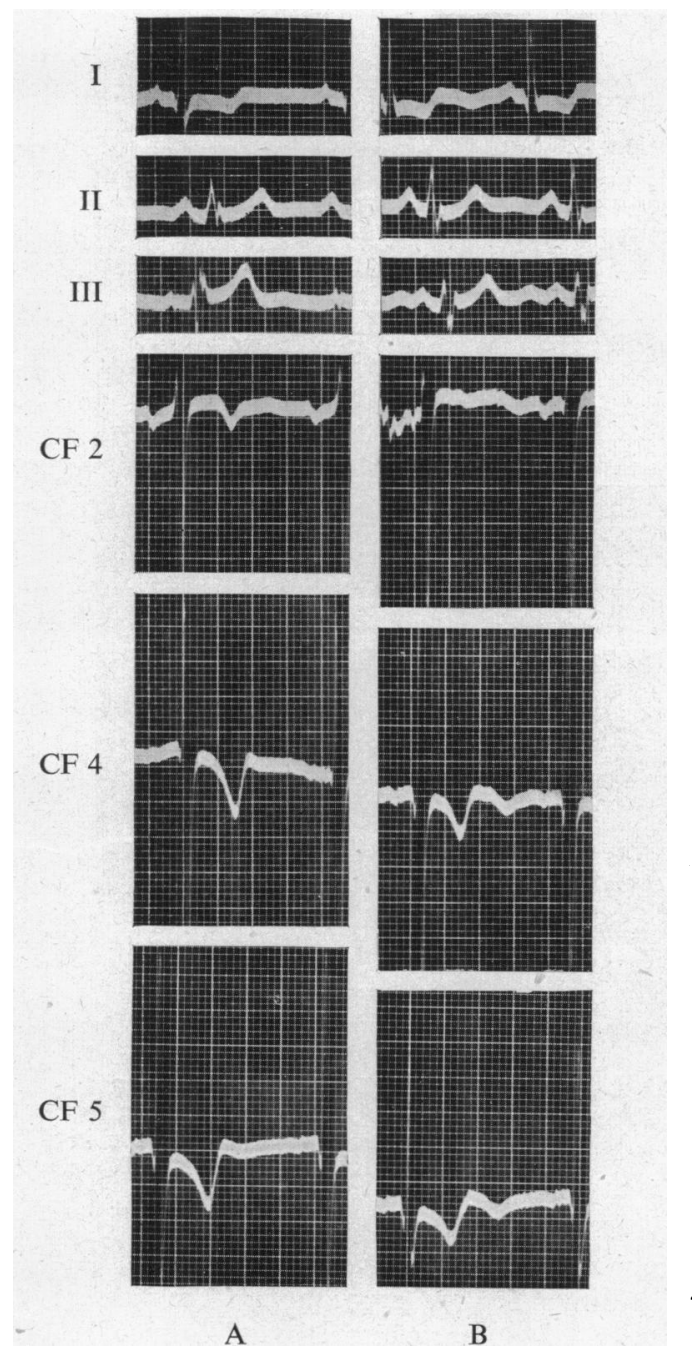

FIG. 1-Case 1. Man, aged 46, with severe hypertension and angina pectoris. Tracings (A) before and (B) immediately after pain-inducing exercise. Note wide QRS. With exercise negative $U$ appears in leads $I$ and CF 2; $U$ becomes more negative in CF 4 and CF 5, and more positive in III. Fig. reduced by $\frac{1}{3}$.

In another patient with mitral stenosis the only additional abnormalities were a large $P$ wave in lead II and a prominent $S$ in lead I; the $U$ wave was only detected when the tracing was compared with a previous one taken when the patient had been digitalized (see Fig. 5).

In none of the tracings made immediately after pain-evoking exercise was inversion of $U$ the sole abnormality. In two cases however the only other findings were a slight depression of the RS-T

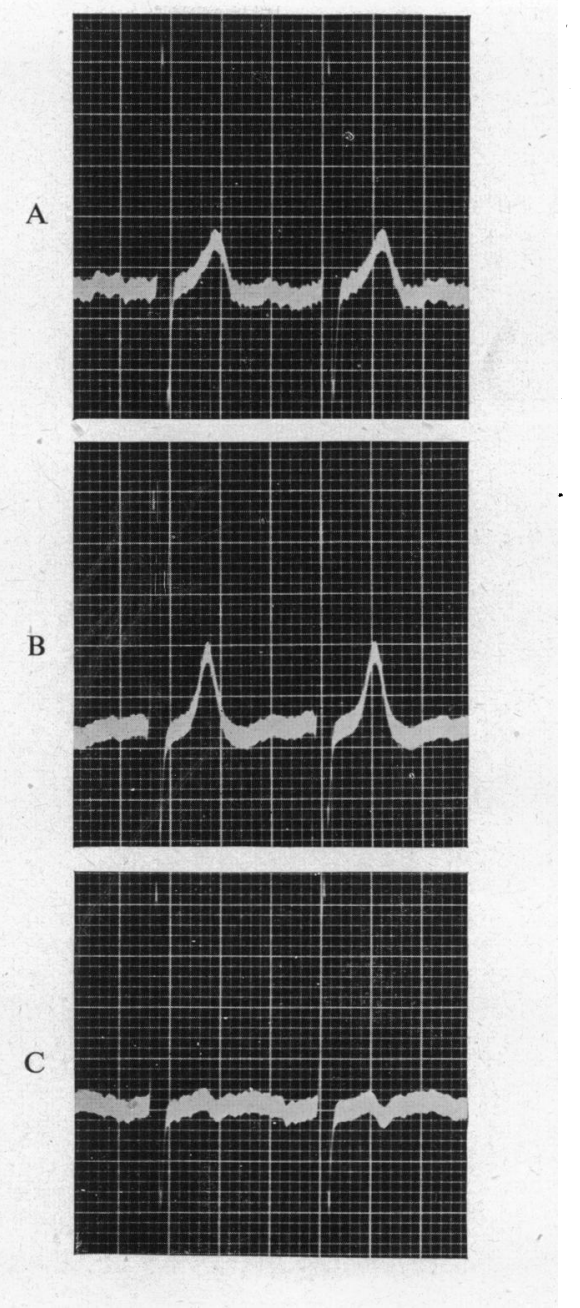

FIG. 2-Case 3. Lead CF 4. (A) Before, (B) immediately after, and (C) five minutes after. Note appearance of " coronary $T$ " and negative $U$ immediately after exercise. Five minutes later $\mathbf{T}$ has become negative and $U$ isoelectric.

segment in lead CF 4; and the appearance of symmetrical $\mathrm{T}$ waves.

\section{Negative U in Intraventricular Block}

$\mathrm{U}$ wave inversion in bundle branch block is described by Nahum and Hoff (1939) and by Papp (1940). Solarz and Elek (1943) failed to find it in 75 consecutive cases of intraventricular block of the S type, but saw it in 17 of 135 cases of the common type: the general pattern was negativity in leads I 


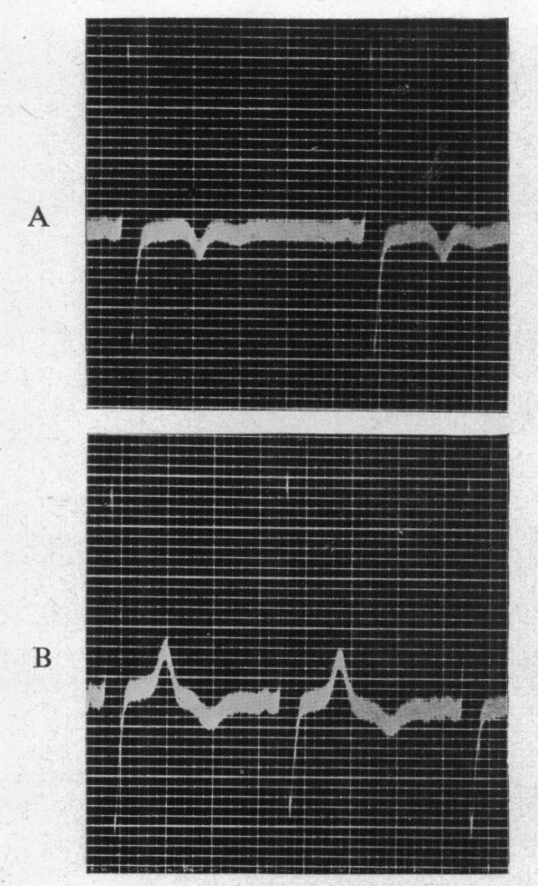

Fig. 3-Case 5. Lead CF 4. (A) Before and (B) after exercise. Note development with exercise of positive "coronary $T$ " concurrently with increase in negativity of $\mathrm{U}$.

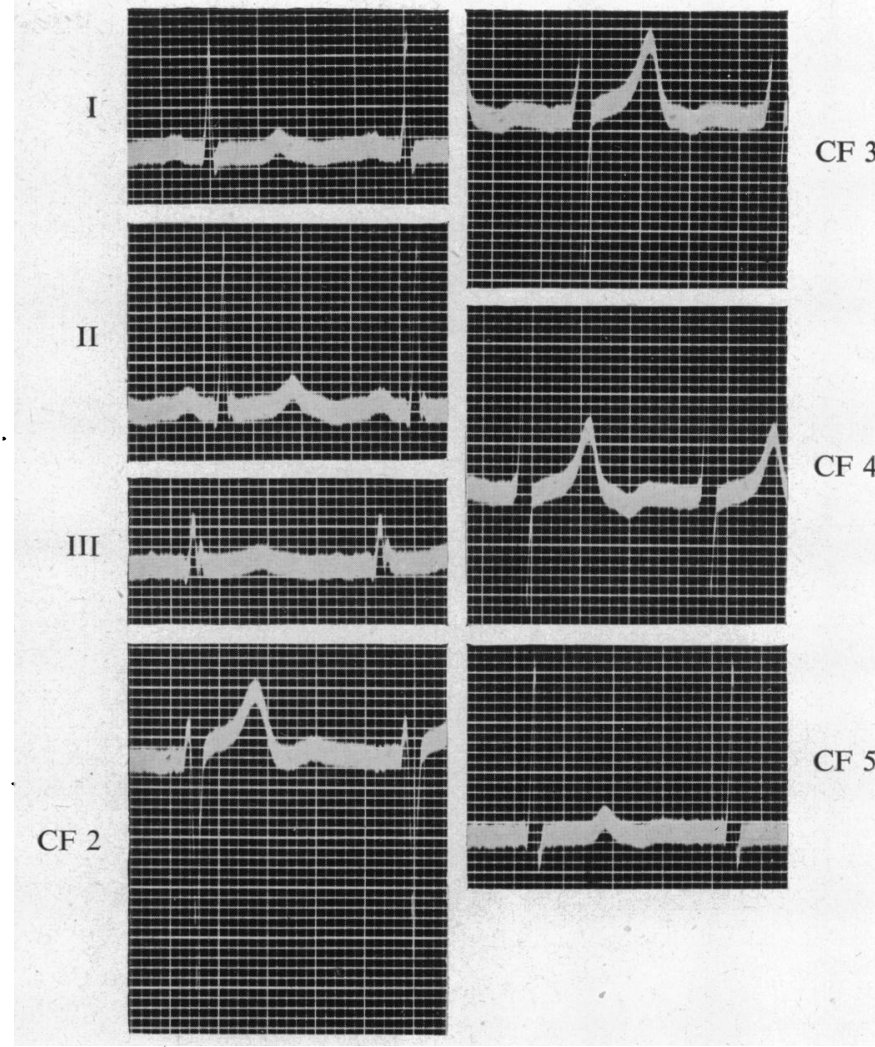

FIG. 4-Case 8. See text. Note $U$ wave inversion as only abnormality: negative $U$ in $I$ and $I I$ and in the left chest leads with diphasic transition $U$ wave in CF 3.

cases that $\mathrm{R}-\mathrm{U}$ was shortened by as much as $\mathbf{0 \cdot 1 2}$ sec. during exercise, even though the heart rate increased only from 62 to 80 , and from 65 to 85 respectively.

\section{Summary AND Conclusions}

The appearance of temporary $U$ wave inversion during anginal attacks induced by exercise is described.

The pattern of $U$ wave inversion seen most frequently is made up of negativity in lead I and in the left chest leads, and positivity in lead III.

The association in individual chest leads of sharply pointed, symmetrical, positive $T$ waves with inverted $\mathrm{U}$ waves in patients with angina pectoris during exercise is described.

Discordancy in direction of development of $\mathrm{T}$ and $\mathrm{U}$ may occur in the chest leads during exercise.

Four cases are described of inversion of $U$ in one or more leads as an isolated electrocardiographic abnormality.
(1940) observation that with exercise the R-U time remains relatively constant irrespective of the heart rate. On the other hand we found in two of our 


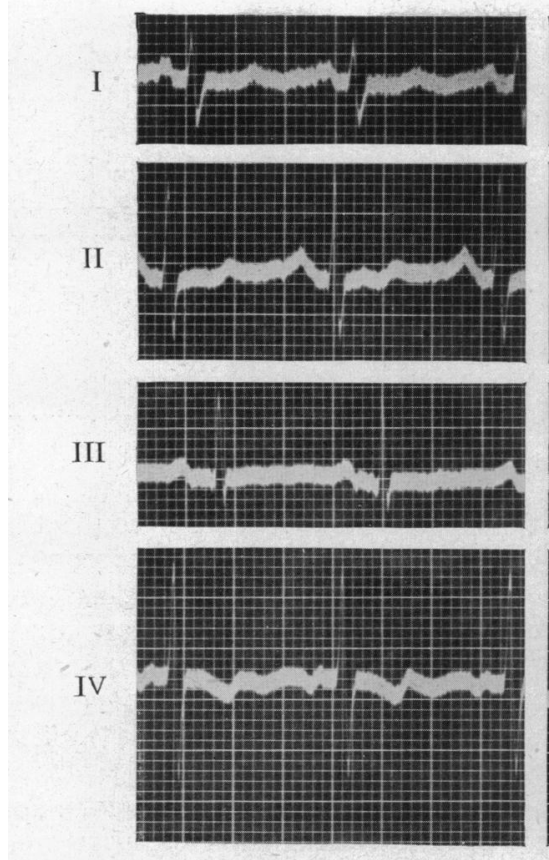

A
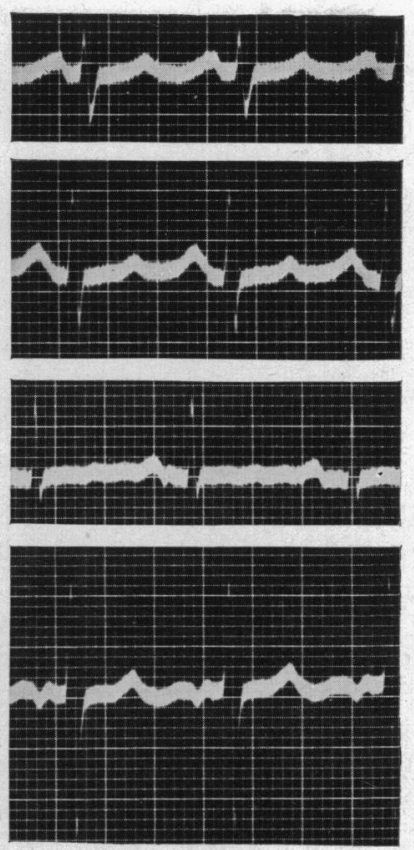

B

FIG. 5-Case 9. Woman, aged 39, with mitral stenosis. Tracings taken (A) during digitalis therapy and (B) ten days after cessation. Note that T IV has become positive but that negative $U$ waves in I and IV have persisted.

Inversion of $U$ when seen in tracings showing bundle branch lesions is probably the result of associated myocardial damage rather than of the conduction defect as such.
The R-U time interval may decrease as the heart rate increases.

Inversion of $U$ in one or more leads should always be considered pathological.

\section{REFERENCES}

Einthoven, W. (1906). Arch. internat. Physiol., 4, 132. Hoff, H. E., and Nahum, L. H. (1938). Amer. J. Physiol., 124, 591.

Katz, L. (1946). Electrocardiography, 2nd ed., Philadelphia, p. 121.
Nahum, L. H., and Hoff, H. E. (1939). Amer. Heart J., $17,585$.

Papp, C. (1940). Brit. Heart J., 2, 9.

Solarz, S. D., and Elek, S. R. (1943). J. Lab. clin. Med., 28, 936 . 